\title{
Effect of Lactose on Soluble-glucan Production and on the Ultrastructure of Sclerotium rolfsii Sacc. Grown in Submerged Culture
}

\author{
By Y. OKON, I. CHET, NAOMI KISLEV AND Y. HENIS \\ Department of Plant Pathology and Microbiology, \\ The Hebrew University of Jerusalem, \\ Faculty of Agriculture, Rehovot, Israel
}

(Received 2 August 1973)

SUMMAR Y

\begin{abstract}
A. significant increase in mycelial dry weight and a decrease in production of extracellular glucan were observed when lactose was added to a submerged culture of Sclerotium rolfsii grown in a liquid glucose-synthetic medium. When added as a sole carbon source, lactose at $2.5 \%(\mathrm{w} / \mathrm{v})$ induced the formation of dark, spherical, compact bodies. The ultrastructure of these bodies is compared with that of sclerotia formed on solid media.
\end{abstract}

\section{INTRODUCTION}

Usually sclerotium formation and sporulation in fungi takes place on the surface of solid media rather than in submerged cultures. Submerged conidiation or sclerotium formation would greatly facilitate the investigation of biochemical events occurring during differentiation. The conidiation of Aspergillus niger in submerged culture has been reported by Galbraith \& Smith (1969). Chet \& Rusch (1969) induced spherule formation in the slime mould Physarum polycephalum by adding $0.5 \mathrm{M}$-mannitol to a synthetic liquid medium. Addition of lactose to the growth medium resulted in synchronous formation of sclerotia in Sclerotium rolfsii (Okon, Chet \& Henis, 1972), sclerotia being formed at the edge of the growing colony. The purpose of this study was to examine the effect of lactose on $S$. rolfsii in submerged culture.

\section{METHODS}

Growing conditions and chemical analysis. Sclerotium rolfsii was grown in $250 \mathrm{ml}$ Erlenmeyer flasks containing $50 \mathrm{ml}$ synthetic medium (SM) (Okon, Chet \& Henis, 1973). These were inoculated with mycelial discs, I cm diam, obtained from a colony of $S$. rolfsii grown on solidified SM, and the flasks were shaken (I 20 strokes $/ \mathrm{min}$ ) for 7 days at $30^{\circ} \mathrm{C}$. The culture was centrifuged at $800 \mathrm{~g}$ for $10 \mathrm{~min}$ and the propagules washed three times by centrifugation with sterile tap water. The inoculum prepared from this material and used for all other experiments was a $2 \mathrm{ml}$ fungal suspension containing $20 \mathrm{mg}$ dry wt. After 7 days, cultures were centrifuged at $800 \mathrm{~g}$ for $\mathrm{I} 0 \mathrm{~min}$ and the mycelium was washed three times in tap water, dried at $80{ }^{\circ} \mathrm{C}$ for $24 \mathrm{~h}$, and weighed. Wall material was obtained by the method described by Chet, Henis \& Mitchell (1967). Water-soluble extracellular polysaccharides were precipitated by centrifugation after adding 2 vol. of cold ethanol to the mycelium-free medium. The precipitate was washed three times with cold ethanol, lyophilized, and weighed. Twenty $\mathrm{mg}$ of either extracellular polysaccharide or mycelial walls were hydrolysed in $2 \mathrm{ml}$ of $4 \mathrm{~N}-\mathrm{HCl}$ at $100{ }^{\circ} \mathrm{C}$ for $5 \mathrm{~h}$. The hydrolysate was neutralized, 


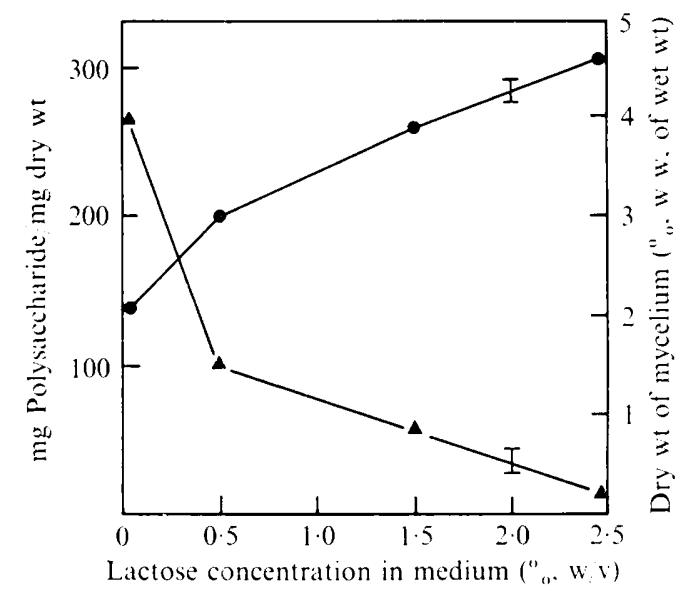

Fig. I. Effect of lactose added to a synthetic liquid medium on mycelial dry weight and solublepolysaccharide production by Sclerotium rolfsii.

$\boldsymbol{\Lambda}$, Polysaccharide;

, dry weight.

and analysed for reducing sugars by descending paper chromatography with benzene: butanol:pyridine:water ( $\mathrm{I}: 5: 3: 3$, by vol.) as a running solvent, and with $\mathrm{AgNO}_{3}$ (I\% in acetone solution) and $\mathrm{NaOH}(2 \%$ in ethanol solution) as developing reagents. Glucose was determined by a glucostat reagent (Worthington Co., New Jersey, U.S.A.) and glucosamine was measured according to Elson \& Morgan (1933). All experiments were carried out three times, each in five replicates.

Transmission electron microscopy (TEM). Cultures of Sclerotium rolfsii were fixed for $2 \mathrm{~h}$ in cold $5 \%$ glutaraldehyde in $0.1 \mathrm{M}$-phosphate buffer $(\mathrm{pH} 7 \cdot 0$ ), rinsed with buffer, and postfixed for $20 \mathrm{~h}$ with $2 \%$ osmium tetroxide in the same buffer. In some experiments the samples were fixed for $\mathrm{I} h$ at room temperature with a mixture (I $\mathrm{I}, \mathrm{v} / \mathrm{v}$ ) of freshly prepared $7 \%$ glutaraldehyde and $4 \%$ osmium tetroxide in $0.1 \mathrm{M}$-phosphate buffer $(\mathrm{pH} \mathrm{7.0)}$. The fixed material was rinsed, dehydrated with ethanol and embedded in Epon 8I2. Thin sections were prepared with an LKB Ultratome III, stained with uranyl acetate and lead citrate and observed in a Y.E.M.T. 7 electron microscope. Thick sections were cut in the same way, stained with toluidine blue, and observed by light and phase microscopy.

Scanning electron microscopy (SEM). Samples from submerged cultures were blotted and attached to the microscope specimen stubs. For comparison, sclerotia of different ages from cultures grown on Petri dishes were taken and treated in the same way. The samples were frozen in liquid nitrogen for a few minutes and lyophilized for $3 \mathrm{~h}$. Some samples were fixed (before freezing and drying) in the same way as material prepared for TEM. For observations of internal structures, samples from shaken flasks were opened with needles, while sclerotia were cut with a razor blade before freezing and drying. The dried samples were coated with a thin layer of gold and observed in a Cambridge Stereoscan electron microscope (SEM) $\mathrm{S}_{4}$ at 10 or $20 \mathrm{kV}$.

\section{RESULTS}

Increasing lactose concentration in the growth medium increased mycelial dry weight and lowered production of extracellular glucan (Fig. I). The addition of lactose to the growth medium also resulted in the colour of the mycelium changing from white through yellow to dark brown. 
Chromatographic and chemical analysis of the hydrolysed extracellular polysaccharide and mycelial wall of all preparations revealed the presence of glucose and glucosamine but not galactose. No significant differences in the ratio of glucose to glucosamine were observed in the tested preparations. Sclerotium formation was not seen even after growing cultures for 2 months in shaken flasks containing media used to induce conidiation in Aspergillus niger (Galbraith \& Smith, I969) or spherule formation in Physarum polycephalum (Chet \& Rusch, 1969).

When the fungus was grown for 2 weeks on SM containing lactose $(2.5 \%$, w/v) as sole carbon source, growth was poor ( $40 \mathrm{mg}$ total dry weight as compared with $275 \mathrm{mg}$ in the glucose medium). On this medium, however, Sclerotium rolfsii produced dark, spherical, compact structures, I to $3 \mathrm{~mm}$ diam (Fig. 2) in contrast to big white propagules formed on SM (Fig. 3). The SEM revealed that their structure was different from that of sclerotia obtained from a culture grown on solidified SM (compare Fig. 2 and 3 to Fig. 4 and 5). Lactose-grown cultures had a central mass of cells surrounded by loosely interwoven hyphae (Fig. 2).

Immature (white) and mature (brown-black) sclerotia kept their rounded structure even when desiccated at room temperature (Fig. 4 and 5). Observation of thick sections by light and phase-contrast microscopy revealed mycelium built of loosely arranged short hyphae with many branches. Large rounded cells, 6 to $20 \mathrm{~nm}$ in diam, were found scattered in the compact bodies (Fig. 6). There were far fewer in controls without lactose. TEM photographs showed that most of the large cells were empty or had very large vacuoles and only a thin layer of cytoplasm (Fig. 7).

\section{DISCUSSION}

Cultures of Sclerotium rolfsii grown on a lactose-supplemented solid synthetic medium showed increased hyphal branching (Henis, Okon \& Chet, 1973) and synchronous sclerotium formation (Okon et al. 1972). In submerged cultures, lactose increased mycelial dry weight and decreased the production of an extracellular soluble glucan.

Tatum, Barratt \& Cutter (1949) found that sorbose restricted the size of fungal colonies in Neurospora by restricting apical growth of hyphae and increasing the degree of branching. In the fungus Podospora anserina, sorbose, galactose and 2-D-deoxyglucose inhibited elongation and enhanced branching of hyphae (Lysek \& Esser, 197I), probably as a result of competitive inhibition of polysaccharide synthesis by these sugars (Johnson, 1968; Lysek \& Esser, 1971). Addition of glucose inhibited the effect of both lactose (Okon et al. 1972) and galactose (Lysek \& Esser, I971). This leads to the assumption that lactose acts similarly as a competitive inhibitor of $\beta$-D-glucan production.

Sclerotium rolfsii, grown in submerged cultures containing lactose, produced compact spherical structures built of interwoven mycelium. When grown on solid SM, the fungus formed brown, hard-walled sclerotia consisting of organized layers of cells (Chet, Henis \& Kislev, 1969). The morphology of the compact bodies reminds one of sclerotia, but microscopical observation showed no typical organization.

The many unusually large cells observed on these bodies were similar to those found in the fungus Dendryphiella salina (Holligan \& Jennings, 1972). So far, the relationship between sclerotia and the compact structure obtained under submerged conditions in lactosecontaining medium, as well as the reason(s) for the inability of Sclerotium rolfsii to form typical sclerotia in submerged conditions remain obscure. Oxygen supply and relative humidity are probably involved and deserve further investigation. 

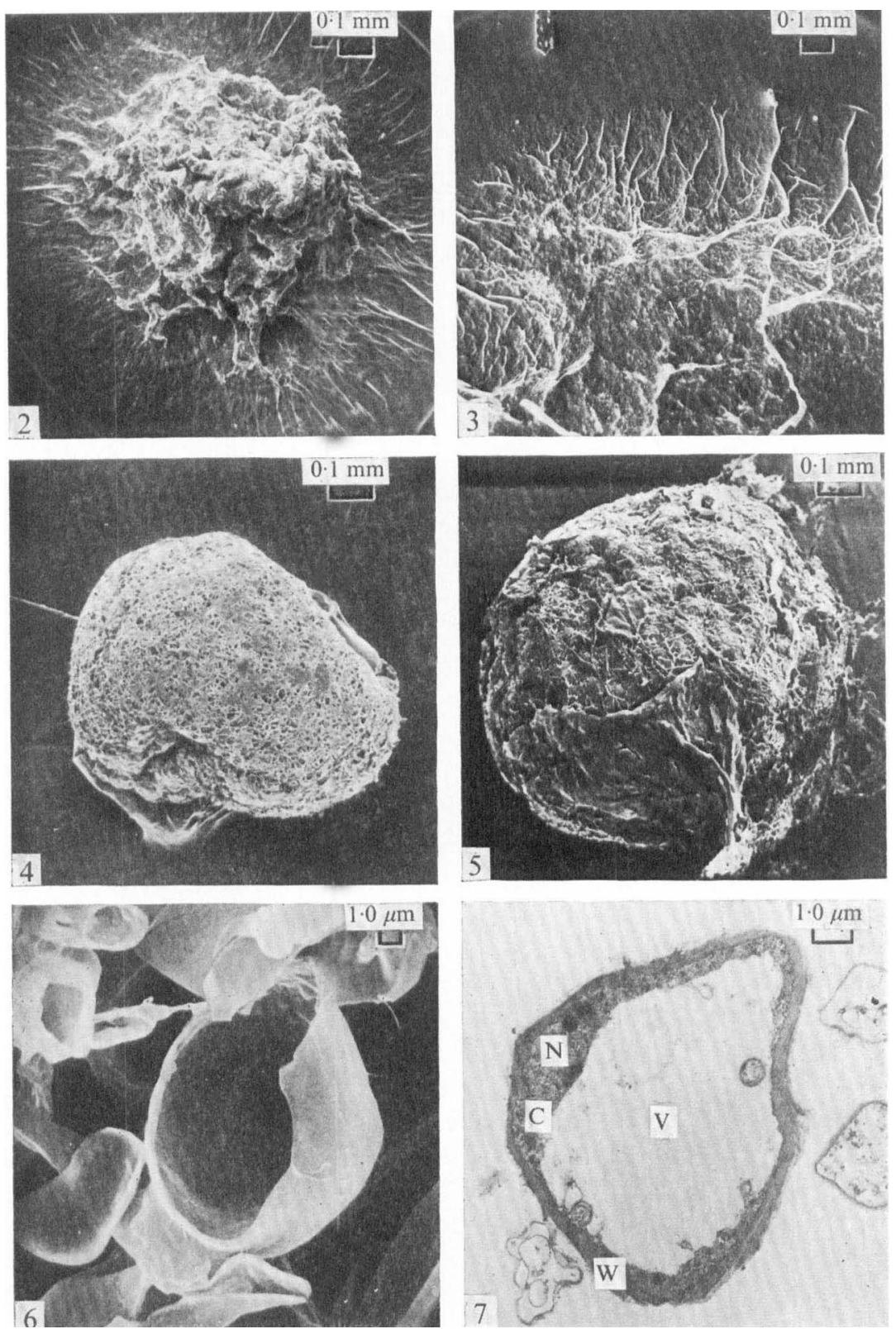

Fig. 2. Scanning electron microscope (SEM) photograph of a compact body of Sclerotium rolfsii grown in lactose supplemented liquid medium.

Fig. 3. SEM photograph of part of mycelial propagule grown in liquid SM.

Fig. 4. SEM photograph of young sclerotium grown on solid SM.

Fig. 5. SEM photograph of mature sclerotium grown on solid SM.

Fig. 6. SEM photograph of broken big cell in the compact body.

Fig. 7. Transmission electron microscope photograph of section of big cell from the compact body. N, nucleus; V, vacuole; C, cytoplasm; W, cell wall. 


\section{REFERENCES}

Chet, I., Henis, Y. \& Kislev, N. (1969). Ultrastructure of sclerotia and hyphae of Sclerotium rolfsii Sacc. Journal of General Microbiology 57, I43-I47.

Chet, I., HeNis, Y. \& Mitchell, R. (I967). Chemical composition of hyphal and sclerotial walls of Sclerotium rolfsii Sacc. Canadian Journal of Microbiology 13, I37-14I.

Chet, I. \& Rusch, H. P. (I969). Induction of spherule formation in Physarum polycephalum. Journal of Bacteriology 100, 673-678.

ELSON, L. A. \& MORGaN, W. T. (1933). A colorimetric method for the determination of glucosamine and chondrosamine. Biochemical Journal 27, 1824-1828.

Galbraith, J. C. \& Smith, J. E. (1969). Sporulation of Aspergillus niger in submerged liquid culture. Journal of General Microbiology 59, 3I-45.

Henss, Y., OKON, Y. \& CHET, I. (1973). The relationship between early hyphal branching and formation of sclerotia in Sclerotium rolfsii. Journal of General Microbiology 79, I47-150.

Holligan, P. M. \& Jennings, D. H. (1972). Carbohydrate metabolism in the fungus Dendryphiella salina. New Phytologist 71, 569-582.

JoHnson, B. F. (1968). Lysis of yeast cell walls induced by 2-deoxyglucose at their sites of glucan synthesis. Journal of Bacteriology 95, 1169-1172.

LYSEK, G. \& EsSER, K. (197I). Rhythmic mycelial growth in Podospora anserina. II. Evidence for a correlation with carbohydrate metabolism. Archiv fiir Mikrobiologie 75, 360-373.

OкоN, Y., Снет, I. \& Henis, Y. (I972). Lactose-induced synchronous sclerotium formation in Sclerotium rolfsii and its inhibition by ethanol. Journal of General Microbiology 7r, 465-470.

OKon, Y., CHET, I. \& HENIS, Y. (1973). Effect of lactose, ethanol and cycloheximide on translocation pattern of radioactive compounds and sclerotium formation in Sclerotium rolfsii. Journal of General Microbiology 74, $25 \mathrm{I}-258$.

Tatum, E. L., Barratt, R. W. \& Cutter, V. M. (1949). Chemical induction of colonial paramorphs in Neurospora and Syncephalastrum. Science, New York ro9, 509-5I I. 